JWAM

Received 20 June 2019 Revised 10 September 2019 15 September 2019 Accepted 15 September 2019
11,2

\section{Inclusion through use and membership of co-working spaces}

\author{
Debora Jeske \\ School of Applied Psychology, University College Cork, Cork, Ireland, and \\ Theresa Ruwe \\ Department of Psychology, Lund University, Lund, Sweden
}

\begin{abstract}
Purpose - The purpose of this paper is to provide an overview of co-working trends, drivers, and explore how the use of such workspaces may support employers wishing to increase the sense of belonging and acceptance of their mobile workers at work.

Design/methodology/approach - This conceptual paper reviews recent literature on co-working, relating this trend to changes in the nature of work, property management and the use of workplaces by employees. A particular focus concerns the social aspects of co-working which may be critical for supporting mobile workers' sense of inclusion in a work community.

Findings - Co-working spaces provide important sources of support, learning and networking opportunities (and hence inclusion), which may offset the lack of community and opportunities that mobile workers face when working outside the main offices of their employers. The authors outline the practical implications as well as recommendations for employers interested in selecting or organising their own co-working spaces. Several research gaps are also delineated for researchers interested in this area.

Practical implications - The use of independent and consultancy-type co-working spaces offer new working opportunities for mobile workers employed in private, public and community organisations. The creation of corporate co-working spaces also provides new learning opportunities for employers that want to create and promote flexible as well as inclusive working environments for their mobile workers.

Originality/value - The research on co-working is relatively limited to date. The current paper provides an important overview of drivers and several starting point for employers interested in learning more about co-working.
\end{abstract}

Keywords Co-working, Inclusion, Mobile workers

Paper type Conceptual paper

\section{Introduction}

Co-working is a relatively new phenomenon that arose due to significant advancements in technology as well as globalisation (Foertsch, 2011; Garrett et al., 2017; Jylhä et al., 2015). Co-working can be defined as a shared work environment in which people with potentially different professions and from different companies work alongside each other, using the shared space to work but also finding opportunities for social support and networking which arise in a diverse community of people. It involves people working together (Foertsch, 2011), in a place that is not the traditional office. People work independently on tasks while working together in shared offices (Jylhä et al., 2015). Unless these spaces are specifically designed for social innovation purposes (see Houtbeckers, 2017), members do not necessarily work on the same tasks. This new workplace concept has met with significant

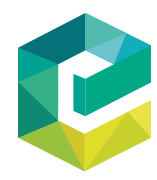

(C) Debora Jeske and Theresa Ruwe. Published in Journal of Work-Applied Management. This article is published under the Creative Commons Attribution (CC BY 4.0) licence. Anyone may reproduce, distribute, translate and create derivative works of this article (for both commercial \& non-commercial purposes), subject to full attribution to the original publication and authors. The full terms of this licence may be seen at http://creativecommons.org/licences/by/4.0/legalcode

Conflict of interest: the authors declare there is no conflict of interest. The authors gratefully acknowledge the support of several colleagues who read this manuscript. The first author would also like to acknowledge the support of the School of Applied Psychology at University College Cork where the ideas for and drafts of this paper were produced as part of an internship project with the second author.
Journal of Work-Applied Management Vol. 11 No. 2 ,
pp. $174-186$ Emerald Publishing Limite 2205-2062

DOI 10.1108/JWAM-06-2019-0021 
success over the last decade. Many of these facilities started off small and increased in size over time, changing both the size of the community and diversity within it (Pohler, 2012). To date, $1.27 \mathrm{~m}$ individuals were working in such spaces by the end of 2017, in 15,500 such spaces globally (Statista, 2018b). By the end of 2018, this number is expected to increase to $1.7 \mathrm{~m}$ members, working in some 19,000 facilities around the world (Foertsch, 2016). These trends highlight the current popularity of these spaces. In addition, according to Foertsch (2018), 29 per cent of all these spaces have opened within the last year. Co-working spaces are clearly increasing in numbers, with most of these located in larger cities. London in the UK already had 1,136 such facilities in 2016 (Statista, 2018a).

The present paper serves as an introduction to co-working trends and motives of mobile workers for using such spaces. The resulting implications and practical guidance presented at the end of the papers for employers are therefore mere starting points to be developed by employers as needed and appropriate to their industries. This paper focusses specifically on the social aspect of co-working and hence the potential of such workspaces to provide a sense of inclusion for mobile workers - a challenge for many employers who are not co-located with their mobile employees. This challenge becomes more apparent when reviewing how inclusion is often defined, namely, as "the degree to which an employee is accepted and treated as an insider by others in a work system" (Pelled et al., 1999, p. 1014). Mobile workers are not necessarily participating in activities within an organisation in the same way that on-site workers are able to do. Another approach is to view inclusion in the context of workgroups (Shore et al., 2011). For the purpose of this paper, we argue that perceived inclusion can be defined as the degree to which the person feels a sense of belonging while also being accepted by their fellow colleagues for their unique characteristics (Shore et al., 2011).

By extending the context within which inclusion can be created, the authors will argue that the use of co-working spaces with support from employers may foster a sense of community for their workers, setting the stage for their inclusion as well as socialisation in new work locations which are not part of the employers' own company sites. The paper therefore considers the use of co-working spaces as a resource for employers and a learning opportunity for organisations wishing to create their own spaces. The next sections introduce the drivers of co-working. Building on this introduction, the link to inclusion is discussed thereafter.

\section{Drivers of co-working}

The purpose of the present section is to provide an overview of general trends that contributed to the development and popularity of co-working and the adoption of such shared workspaces by mobile workers. An important starting point here is tele-working, which can be traced back 20 years, while co-working emerged a few years later. At first glance then, co-working shares many characteristics with tele-working. However, co-working differs from tele-working as co-working is the usually collaborative use of spaces and places shared with other mobile workers (Jylhä et al., 2015). Bueno et al. (2018, p. 453) go further when they state "co-working prioritises the attainment of new capabilities and abilities through cooperation with individuals from different professional and personal backgrounds". Tele-workers also do not work in the same places with others and their contact to others may be limited to computer-mediated means alone.

The emphasis on "togetherness" also allows us to draw a demarcation between co-working and competing alternatives like a home office or so-called "third places" (Oldenburg, 1989), which do not necessarily emphasise the community aspect (Brown, 2017; Garrett et al., 2017). That means these mobile workers will not experience the same social work experience as those in co-working places. Similarly, tele-working is not generally linked to self-employment. Yet, in co-working spaces, self-employed individuals may present 
JWAM

11,2

a significant proportion of users (Bueno et al., 2018). The drivers for mobile working and coworking are numerous, some of these coincide. The most important drivers for both trends concern the following: technological developments, changes in property trends among employers, and the need for and call for more flexible working models by employees.

The first driver is the development of the information technology and network infrastructure, both of which allow for mobile as well remote working across large distances as temporal and spatial limitations disappeared (Al-Hadi and Al-Aufi, 2019). Employees are now able to work remotely (Brown, 2017; Jylhä et al., 2015; Kojo and Nenonen, 2016; Leclercq-Vandelannoitte and Isaac, 2016), with many workers working in numerous locations rather than just traditional offices. This trend has particularly impacted a large number of management and IT consultants, freelancers working in journalism, and many workers employed in precarious employment such as the gig-economy (often also referred to as digital nomads). Many professionals today use modern computing and information technologies that allow for remote working across numerous locations and workplaces (Leclercq-Vandelannoitte and Isaac, 2016), including co-working spaces as these often provide the information infrastructure to facilitate such working practices. Co-working spaces are particularly noteworthy as a resource for mobile workers as they offer both the technical and information infrastructure they require.

The second driving factor refers to a set of changes in urban areas: first, the shift towards urban regeneration (Sans, 2016), and, second, a change in property management approaches prompted by an increase of rental costs in many cities (Appel-Meulenbroek et al., 2019; Brinkoe and Nielsen, 2017), leading many companies to control such costs using alternative approaches to optimise their use of space (Harris, 2015). For many smaller businesses, the costs of renting fixed offices are a significant driver for the acceptance of alternative workplace solutions (Al-Hadi and Al-Aufi, 2019). What is more, economic downturns and increases in rental prices has led many property companies to combine formerly single tenant offices into multi-tenant offices (Appel-Meulenbroek et al., 2019). The advantages for businesses are clear: "Instead of the fixed costs associated with regular long-term leases and facility contracts, serviced offices offer products with flexible contracts that can be classified as variable costs" (Appel-Meulenbroek et al., 2019, p. 5). Many co-working offices have emerged as a result of the emergence of the multi-tenancy market and are part of a subsection of larger serviced office building (Appel-Meulenbroek et al., 2019). Both co-working spaces and regular serviced offices offer similar technical resources to tenants. However, the main difference is that co-working offices are specifically created to support collaboration and interaction (Kojo and Nenonen, 2014).

A third contributing factor concerns changes to work and working models (e.g. adoption of mobile working, the development of independent and freelance work; Leclercq-Vandelannoitte and Isaac, 2016; van de Kar et al., 2017). Indeed, the focus in real estate management has increasingly shifted from managing property to managing services to support workers (Harris, 2016). Workspaces are not no longer just buildings and facilities. Today, they are locations where corporate values and culture are expressed, a place of shared meaning and talent attraction. And related to our co-working perspective, workplaces are now seen as places designed for adaptability, creativity and collaboration (Harris, 2016). This led to the adoption of more social environments such as co-working spaces by many companies (e.g. American companies such as AirBnB, AT\&T, Google, Facebook, IBM, SAP, State Farm, Twitter, UBER and Verizon as well as European companies such as Barclays, Orange and Endesa; Nagy and Lindsay, 2018; Sans, 2016; Di Risio, 2018). As corporate co-working spaces emerged, so did independent co-working operators. One such example is the company WeWork, which started in 2010. The mission of this company is to build a community for their co-workers, many of which are employees of Fortune Global 500 companies (WeWork, 2019), including companies such as Microsoft, Facebook and Starbucks (Di Risio, 2018). 
Today, employees increasingly seek to build and select their own workspaces, choose to work independently, and seek new experiences and a motivational environment during working hours (Al-Hadi and Al-Aufi, 2019; Leclercq-Vandelannoitte and Isaac, 2016; Nenonen and Lindahl, 2017). In terms of changes in working models, these can be attributed to technological developments which affect the structure, nature and pace of work, leading to new ways of working (Marchegiani and Arcese, 2018). For example, many workers prefer to switch locations when they move from one activity to another in order to access the resources or interactions to complete tasks (e.g. when the task is creative or collaborative; Haynes et al., 2019). In addition, work-life balance concerns also change the needs of many mobile workers (Orel, 2019). Co-working spaces are quickly developing in tandem with these trends in work environments and working models, making them important workspaces for employers and mobile employees alike. The community angle is particularly one that is relevant to the concept of inclusion, which is discussed next.

\section{Inclusion via co-working}

In this paper, it is proposed that when employers support mobile workers' use of co-working spaces, they also set the stage for more inclusion that these workers may otherwise not experience in less communal workspaces. Sabharwal (2014, p. 199) explored inclusion in relation to diversity management and argued that "the focus needs to change from an overreliance on policies and structural changes to fostering an environment that promotes inclusiveness". This sentiment also applies to efforts to manage and support the inclusion of mobile workers in their respective workplaces. Doing so may benefit the employer in multiple ways. For example, perceived inclusion has been shown to foster commitment to the organisation (Chen and Tang, 2018), while ratings of perceived inclusion also correlate positively with employee performance at an individual and team level (Chen and Tang, 2018; Pearce and Randel, 2004). Indeed, some corporations now purposefully look towards co-working as a solution in order to benefit from the "co-working formula" which includes community building, a social workplace, and increases revenue and improves the workflow (Sans, 2016). Although the literature does pick up on social needs, knowledge needs, or spatial needs (e.g. Waters-Lynch and Potts, 2017), none of the existing articles on coworking discusses inclusion as a particular topic of note for mobile workers. The present section therefore focusses on the potential of inclusion via co-working.

Professionals want workplaces where they can access support, find collaborators, engage in team work and find social support (Al-Hadi and Al-Aufi, 2019). This is particularly the case for many co-working professionals such as those who are entrepreneurs, freelancers and independent contractors (Bueno et al., 2018). Accordingly, one of the basic premises of the shared spaces is that they will present room for encounters and bring "added value through social interactions" (Jakonen et al., 2017, p. 241). Interactions generate opportunities for networking, socialisation, peer-support or mentoring (Brown, 2017), as well as the exchange of knowledge (Capdevila, 2018; Garrett et al., 2017; Gerdenitsch et al., 2016; Pohler, 2012). These findings support the premise of co-working spaces as a means to promote a sense of inclusion through social support and social interactions (Gerdenitsch et al., 2016). Important values in such spaces are collaboration, openness, community, sustainability (Capdevila, 2018) and mutual trust (Foertsch, 2011).

All of these attributes mean that co-working spaces are a suitable work space for mobile workers who may lack a sense of community and belonging, feel isolated or socially adrift when working alone (Garrett et al., 2017; Leclercq-Vandelannoitte and Isaac, 2016). Indeed, the importance of social motives for mobile workers, such as the need to interact with others and to collaborate, is one of the reasons for the popularity of co-working spaces (Al-Hadi and Al-Aufi, 2019; Liegl, 2014; Spinuzzi, 2012). The discussion around concepts such as workgroup inclusion, perceived organisational inclusion and inclusion practices (e.g. Shore et al., 2018) 
JWAM

11,2

demonstrates that many organisations now seek to build communities and a culture that is inclusive, rather than focussing on smaller employee groups. Co-working provides the contact and the potential for inclusion via the acceptance and proactive support provided by the co-working community. This is where events, community managers (also known as coordinators or hosts) can play a critical role (Capdevila, 2019; Orel, 2019; Orel and Alonso Almeida, 2019; Roth et al., 2019; Walden, 2019). This also fits with Jansen et al.'s (2014, p. 370) argument that "in the process of inclusion, it is the group rather than the individual that has primary agency" This is also in line with Shore et al.'s (2011) argument that belongingness is characterised by acceptance by others and interpersonal relationships. An individual cannot strive for inclusion on its own as social identification with the group does not lead to inclusion. Only the group can provide a sense of belonging by actively welcoming the new individual into the group. By supporting mobile workers' membership of such co-working spaces, employers may therefore enable these workers to maintain a sense of community, have access to on-site support in these spaces and increase their perceived inclusion within the local workspace, ideally in combination with efforts to make the mobile worker feel connected to their employer. Such membership schemes and support may then also increase both the commitment and performance of mobile workers, even if they are generally working in their own respective, off-site workspaces.

\section{Pro and cons of co-working for employers and employees}

The above sections suggest co-working spaces, when utilised strategically, may provide an alternative space for mobile knowledge workers who are on temporary assignments to experience a sense of community and social support (Brown, 2017; Foertsch, 2011; Spinuzzi, 2012). As noted, friendly relationships at work can provide functional and psychological benefits like increased communication, trust and social support (Morrison and Macky, 2017) - setting the stage for employee inclusion. These benefits may also facilitate the socialisation and integration of new arrivals (Malik and Manroop, 2017), and ensure that they have access to support and opportunities for knowledge exchange. Further research with co-workers also demonstrates that social interactions appeared to have a positive influence on the productivity of co-workers (Bueno et al., 2018). Location switching may also enable mobile workers to avoid noise levels and interruptions (Haynes et al., 2019). The use of shared facilities may offer members more flexibility in terms of who uses the spaces when compared to traditional offices. Leclercq-Vandelannoitte and Isaac (2016) also argue that employers wishing to attract a diverse workforce need to provide their employees with a range of workspaces to meet the different expectations of their employees. Co-working facilities may therefore be a useful additional option that employers can opt for in order to meet the needs of their employees.

Nevertheless, it is essential to be aware of some potential challenges, as this paper's premise relies on certain facilitating conditions (see case studies in Jakonen et al., 2017; Marchegiani and Arcese, 2018). Some co-working spaces offer learning opportunities (Marchegiani and Arcese, 2018; Nenonen and Lindahl, 2017; Sans, 2016), but these may not replace the missed learning opportunities that mobile workers could have had on their employer's premises (Raffaele and Connell, 2016; Martinez and Gómez, 2013). Furthermore, some communities may not provide the amount of social support expected, particularly when the members change rapidly, and relationships are tenuous rather than enduring. This means mobile workers in shared facilities may be limited in their time and ability to network and truly benefit from the potential social connections available to them (Jakonen et al., 2017). In addition, it is important to consider the concept of participation, reciprocity and social proximity in terms of which members use shared spaces and engage with the community that they are part of (Parrino, 2015). This also includes paying attention to the extent to which individuals wish to collaborate, share expertise and network with each other (Walden, 2019). 
Other challenges relate to preferred ways of working in co-working spaces over alternative venues such as the home office or "third spaces" (Oldenburg, 1989). Motivations for choosing specific workspaces may vary. While some may wish to separate home and work life (Brown, 2017), others may value the professionalism that goes hand in hand with working in an office-like environment compared to a café. Distractions and the lack of privacy may be an issue in co-working spaces (Harris, 2017), similar to the work experience in many traditional offices (Haynes et al., 2019). Many, but by no means all, members seek the opportunity to meet like-minded people to increase social and peer support (Brown, 2017). This also means the motives of the different membership groups may not always align and needs attention. The next section describes some practical guidance for employers wishing to maximise the pros over the potential cons when choosing co-working spaces for their mobile workers.

\section{Practical implications and recommendations}

National organisations such as the Chartered Institute of Personnel and Development (UK) and many other advocates argue that more need to be done to promote flexible as well as inclusive work practices (Wall, 2017). Indeed, the adoption of co-working may be one option to achieve both flexibility and inclusion. Finding new ways to support the needs of the growing number of mobile workers is particularly important. Co-working spaces present one of several important avenues to address social needs and the desire for knowledge sharing and inclusion among mobile workers. In this section, we will outline some of the practical implications and offer some guidance for employers seeking to support mobile workers and provide them with work communities within which they feel included. We first specify recommendations for those employers who want to offer or even implement co-working spaces themselves. Following this, we focus on guidance for those employers who want to foster the inclusion of mobile workers without necessarily using co-working as an approach.

\section{Selecting co-working sites}

Employers who wish to support mobile workers (but do not wish to rent co-working spaces for their workers) may need to identify ways to address the needs of mobile workers compared to their stationary colleagues. A number of strategies may be helpful for managers tasked with providing support to mobile workers (see also Haynes et al., 2019; Wohlers and Hertel, 2017). First, employers wishing to support the adoption of co-working spaces and support their employees' use of these may wish to familiarise themselves with the literature on co-working and other shared space approaches. The work by Bueno et al. (2018) provides a good overview of the co-working history for readers unfamiliar with these concepts. Following this, they may wish to identify workspaces within reach of mobile workers. Learning about existing sharing practices of these shared spaces (Brinkoe and Nielsen, 2017) may help in this process. Capdevila (2019) provides an overview of the different collaborative spaces that may promote knowledge sharing and collaboration. The third step would be to reach out to community managers of selected places (Šviráková et al., 2015), and pre-vet spaces with respect to the resources that their mobile workers will need. This may even include identifying spaces where co-workers jointly create and take responsibility for self-organised daily childcare (Orel, 2019). Knowing the job and work requirements of their workers, employers may then be more readily able to identify those spaces that are suitable and arrange for memberships in the appropriate locations.

One possibility would be worth keeping in mind. As Capdevila (2019, p. 17) noted, co-working spaces are essentially "platforms of collective participation that benefit their local community". Many co-working spaces are designed with the public in mind (Malik et al., 2016), featuring not just workspace but also meeting rooms, social places and community kitchens (Nenonen and Lindahl, 2017). Employers wishing to support 
JWAM

11,2

co-working opportunities for their employees may find it useful to research membership opportunities in local co-working spaces. Indeed, many universities and libraries have spaces that allow for co-working, even though these spaces may be not be called "co-working spaces" but learning hubs or similar (Brinkoe and Nielsen, 2017; Capdevila, 2019). This means that is it likely that employers will find local champions at public institutions. These contact points may enable employers to get a sense of which provisions are adopted, available and which shared spaces may be compatible with the needs of their mobile workers. They are also very likely to understand the need of employees in co-working spaces to interact, socialise and also collaborate with others - all elements that are critical for the design process of such spaces (Appel-Meulenbroek et al., 2019; Weijs-Perrée et al., 2017). This approach recognises that "even though the movement of co-working is a global one, the dynamics of co-working spaces remain very local and very contextual" (Nenonen and Lindahl, 2017, p. 309).

\section{Creating a co-working space}

In the beginning, co-working facilities were used by freelancers, start-ups and knowledge workers in the creative industries (Moriset, 2013). Nowadays, 36 per cent of the members are corporate employees, compared to 41 per cent of freelancers. Moreover, the trend of co-working has started to spread into other disciplines and sectors (Cerdeira, 2017). For instance, IT jobs (22 per cent), marketing, sales and public relations (14 per cent) are now represented in such spaces. As a result, a number of different types of co-working spaces have emerged, including co-working spaces that are specifically supported and funded by companies (Nagy and Lindsay, 2018; Nagy, 2019).

Which co-working model works best may depend on the number of mobile workers that need to be supported and the interests of the employer. Bouncken et al. (2018) distinguish between four types: "independent co-working spaces", "consultancy", "open corporate" and "corporate". Each of these types indicates the degree of company involvement and the extent to which the spaces are a social as well as expert space. The original and most well-known type includes "independent co-working spaces" that truly embrace the aspect of "togetherness". These spaces are characterised as a social space where members have both a workspace and a community. These spaces are not necessarily sponsored by specific companies for their employees, but are open to anybody, anywhere. Smaller employers may wish to create such spaces in collaboration with many small businesses to share costs. Start-up hubs may be a suitable location for such spaces as there will be more freelancers and entrepreneurs in the area that may get on board (van de Kar et al., 2017). As independent spaces are meant to be open to all, employers do not have necessarily the ability to influence how the membership number and diversity will develop over time. As a result, this type of co-working space may be particularly of interest to those employers open to experience and experimentation, who have smaller number of mobile workers in their employment, and wish to collaborate with other businesses.

The social component is also prominent in the second type, so-called "consultancy spaces" (Bouncken Laudien et al., 2018). These are largely sponsored by companies who wish to provide their employees with opportunities to build professional relationships and networks through affiliation with such spaces and communities. Here, members are encouraged to create ties and relationships within a social environment. Brown (2017) also notes the importance of co-worker complementarity and compatibility among co-workers, aspects that may play a particular role in this type of environment. Indeed, particularly in the "consultancy" and "independent" spaces, members' social behaviour may influence the experience and type of interactions between all community members. That is, both managerial and members' own practices are socially constructed (Wall, 2016). According to Garrett et al. (2017), each member has the option to engage with, endorse or merely 
encounter (be a passive member of) the community. Medium-sized to larger employers may find "consultancy spaces" a better option than "independent" spaces when they employ larger number of mobile workers that will be using the same co-working spaces.

Co-working has become more prevalent, to the point where companies are starting to open their own "corporate" spaces (see also introduction to this paper and work by Harris, 2017; Leclercq-Vandelannoitte and Isaac, 2016). Their membership fees often vary and may be paid by the individuals or their employers (Garrett et al., 2017). While some of these co-working spaces may be closed, most of these are "open corporate" spaces whose members may not necessarily be affiliated with the main sponsor company. In this case, companies encouraged members outside their workforce to join and extend creativity and thinking. Within the "corporate" type, the focus lies on creativity and entrepreneurship, areas that may be specific to the respective company or companies sponsoring this space. This may be an option for larger employers. There are examples of competing companies signing up for "open corporate" co-working spaces in the spirit of coopetition, that is, collaborative but also competitive open innovation (Roth et al., 2019). Whether or not this will make these co-working space more or less attractive to mobile workers will have to be decided on a case-by-case basis (see also Nagy, 2019).

If the employer takes the step to create their own co-working space, they will thus have to decide which kind of co-working space they want to create (see also the work by Nagy and Lindsay 2018). In addition to hiring community managers (Nagy and Lindsay, 2018), existing co-working operators (Hillman, 2019) suggest that including belonging in the code of conduct of a co-working space is important to ensure inclusion at the workplace. Corporate co-working spaces do not work unless an actual co-working culture catering to inclusion, openness, exchange and support are developed Providing flexible infrastructure that caters to a variety of needs (e.g. ability to change layout, private vs social spaces) are another important consideration (Sans, 2016). The infrastructure must create opportunities for cooperation, collaboration, and networking (Di Risio, 2018). A close collaboration between researchers and organisers of co-working spaces may offer opportunities for learning. The mere presence of researchers can, through their interactions with all parties, trigger reflection on goals and values (Wall et al., 2017). These elements can help employers to understand what is needed for a co-working space to be adopted by mobile workers, which values they want co-workers to adopt and how they want their workers to use the space.

\section{Supporting mobile workers generally}

Even if co-working is not the approach selected, several options exist to enable employers to support their mobile workers and ensure they feel included. This includes the formulation and implementation of shared goals and institutional support to foster inclusion of all workers (Kokkonen et al., 2015). Furthermore, some insights based on the co-working findings to date may generate useful starting points for employers.

First, in many co-working settings, community managers provide activities and tools that facilitate informal relationship creation (Merkel, 2015; Spinuzzi, 2012). In this process, they actively construct the social experience of those within this work environment and thus activate expectations of the workers who are using these workplaces (Wall, 2016). These serve to reduce isolation and stimulate an environment of social proximity (Parrino, 2015). This role could be taken on by engagement managers within companies. Involving these professionals may enable managers to identify ideas and approaches that would create a sense of social cohesion and belonging for mobile workers using online events, exchange platforms and facilitate regular interactions among colleagues that include the mobile workers. Managers will have to play a critical role in this process to get their employees to participate and collaborate in this process (see also Capdevila, 2019). In addition, it is important that supervisors of mobile workers monitor the amount of training provided to
Co-working spaces 
JWAM

11,2

their mobile workers when they spend significant time away from the office (see also recommendations by Martinez and Gómez, 2013). And, second, the use of social platforms in the workplace provides an opportunity to introduce members to one another, which may then also contribute to the creation and building of relationships (Ferro, 2016). This may further foster the inclusion of mobile workers even if they are not part of regular workplace interactions or work in a co-working space. Additional resources are available for managers responsible for workplace design and service delivery who seek further information on trends in design and mobility (Orel and Alonso Almeida, 2019; Petrulaitiene et al., 2018).

\section{Future research}

Co-working is a relatively new workspace concept. Many articles tend to paint a positive picture; the limits and barriers are worth exploring in more detail in order to gain a more critical but realistic sense of when such approaches are an option. While a few noteworthy resources exist for practitioners interested in co-working (worthwhile readings are Bouncken and Reuschl, 2018; Gandini, 2015; Marchegiani and Arcese, 2018; Spinuzzi, 2012), many questions still remain. For example, despite the rapid increase in the number of co-working spaces, there are not enough research papers on co-working available at present to allow for country-specific, sector or employer comparisons. Those that exist often concentrate on city, municipal or community developments (Brinkoe and Nielsen, 2017), rather than comparative analyses. More comparative work would be helpful to understand under which circumstances (design, location, membership and community management) co-working spaces are likely to succeed and how these spaces attract individual or corporate members.

Several specific questions furthermore arise in terms of these selection, socialisation and attrition questions. For example, one question concerns the extent to which co-workers share similar or the same goals when joining a co-working space (e.g. seeking avenues for collaboration, ideas for creativity and innovation), possibly as a function of the type of co-working space (e.g. such as "consultancy" vs "independent" spaces). Another question pertains to how important equal status and mutual understanding of joint priorities and workplace etiquette are for co-workers when they select a space. Relatedly, it would be interesting to examine if co-working spaces also exhibit hierarchical membership relationships similar to traditional workplace and how expectations about workplace etiquette are communicated (Walden, 2019). And, lastly, longitudinal (such as qualitative and ethnographic) studies may help chart the development of co-working communities (Brown, 2017), the role of national contexts (Bouncken Laudien et al., 2018), and technological drivers as well as social practices (Al-Hadi and Al-Aufi, 2019; Leclercq-Vandelannoitte and Isaac, 2016; Merkel, 2015). Such work would also expand our current understanding of the factors that drive the adoption of co-working spaces by mobile workers and employers.

Moreover, while several articles and press reports cover the social aspects (e.g. Merkel, 2015; Parrino, 2015), none really address the premise of co-working as a means to achieve social inclusion as a key theme in a similar vein to the current article. For interested researchers, a few questions to address are therefore the following. What is the evidence that co-workers want and share similar social needs? There are likely to be differences in perceptions and goals between those members that will actively support the community through events and activities in order to create a sense of togetherness, compared to more passive members that may utilise the benefits of such facilities without actively contributing to them. Does the type of co-working space influence belonging and thus inclusion perceptions? Further, do the consequences of exclusion of individuals by the group in a co-working space have the same negative effects on the individuals as exclusion in a traditional workgroup? This highlights the need for more work in the area of how members of groups negotiate their needs and which aspects of shared spaces support positive social interaction (Brown, 2017; Gerdenitsch et al., 2016). 
Further exploration of the variables, which facilitate social interaction in these workspaces, such as personal preferences or spatial needs, may enable organisations to learn about how such features could be brought back and potentially implemented within the main organisation that employs knowledge workers (Gerdenitsch et al., 2016). Particularly, given the possible cultural diversity between members in more international shared spaces in many major cities (see also Kojo and Nenonen, 2016), it would be helpful to learn more about the cultural factors which come into play when mobile workers choose their own spaces and how their work translates into effective performance (Nenonen and Lindahl, 2017).

\section{References}

Al-Hadi, N. and Al-Aufi, A. (2019), "Information context and socio-technical practice of digital nomads", Global Knowledge, Memory and Communication, Vol. 68 Nos 4/5, pp. 431-450.

Appel-Meulenbroek, R., van de Kar, M., van den Berg, P. and Arentze, T. (2019), 'Employees' preferences for services and facilities offered in serviced offices”, Facilities, Vol. 37 Nos 1/2, pp. 3-20.

Bouncken, R.B. and Reuschl, A.J. (2018), "Coworking-spaces: how a phenomenon of the sharing economy builds a novel trend for the workplace and for entrepreneurship", Review of Managerial Science, Vol. 12 No. 1, pp. 317-334.

Bouncken, R.B., Laudien, S.M., Fredrich, V. and Görmar, L. (2018), "Coopetition in coworking spaces: value creation and appropriation tensions in an entrepreneurial space", Review of Managerial Science, Vol. 12 No. 2, pp. 385-410.

Brinkoe, R. and Nielsen, S. (2017), "The characteristics to consider in municipal shared spaces", Journal of Facilities Management, Vol. 15 No. 4, pp. 335-351.

Brown, J. (2017), "Curating the "third place'? Coworking and the mediation of creativity", Geoforum, Vol. 82, June, pp. 112-126, available at: www.sciencedirect.com/science/article/pii/S00167185 17300866

Bueno, S., Rodríguez-Baltanás, G. and Gallego, M. (2018), "Coworking spaces: a new way of achieving productivity”, Journal of Facilities Management, Vol. 16 No. 4, pp. 452-466.

Capdevila, I. (2018), "Knowing communities and the innovative capacity of cities", City, Culture and Society, Vol. 13, June, pp. 8-12.

Capdevila, I. (2019), "Joining a collaborative space: is it really a better place to work?", Journal of Business Strategy, Vol. 40 No. 2, pp. 14-21.

Cerdeira, S. (2017), "Five trends for coworking spaces in 2017", 1 January, available at: http://blog. worktel.com/five-trends-for-coworking-spaces-in-2017/ (accessed 4 January 2018).

Chen, C. and Tang, N. (2018), "Does perceived inclusion matter in the workplace?", Journal of Managerial Psychology, Vol. 33 No. 1, pp. 43-57.

Di Risio, A. (2018), "Understanding the corporate coworking client”, 26 September 2016, available at: www.coworkingresources.org/blog/understanding-the-corporate-coworking-client (accessed 8 September 2019).

Ferro, T. (2016), "Knowledge workers and associative activity: an examination of knowledge work systems and settings", dissertation, University of Washington Department of Human Centered Design \& Engineering, Washington, DC.

Foertsch, C. (2011), "What is coworking and its cultural background?", 10 May, available at: www.deskmag.com/en/what-is-coworking-about-the-changing-labor-market-208 (accessed 4 January 2018).

Foertsch, C. (2016), "First results of the 2017 global coworking survey", 6 December, available at: www.slideshare.net/carstenfoertsch/the-first-results-of-the-2017-global-coworking-survey (accessed 4 January 2018). 
JWAM

11,2

184

Foertsch, C. (2018), "1.7 million members will work in co-working spaces by the end of 2018", 22 February, available at: www.deskmag.com/en/1-7-million-members-will-work-in-coworkingspaces-by-the-end-of-2018-survey (accessed 26 April 2018).

Gandini, A. (2015), "The rise of coworking spaces: a literature review", Ephemera: Theory and Politics in Organization, Vol. 15 No. 1, pp. 193-205.

Garrett, L.E., Spreitzer, G.M. and Bacevice, P.A. (2017), "Co-constructing a sense of community at work: the emergence of community in coworking spaces", Organization Studies, Vol. 38 No. 6, pp. 821-842.

Gerdenitsch, C., Scheel, T.E., Andorfer, J. and Korunka, C. (2016), "Coworking spaces: a source of social support for independent professionals”, Frontiers in Psychology, Vol. 7 No. 25, pp. 1-12.

Harris, A. (2017), "What are the pros + cons of shared office space?", available at: www.rocketspace. com/tech-startups/what-are-the-pros-cons-of-shared-office-space (accessed 4 January 2018).

Harris, R. (2015), "The changing nature of the workplace and the future of office space", Journal of Property Investment \& Finance, Vol. 33 No. 5, pp. 424-435.

Harris, R. (2016), "New organisations and new workplaces", Journal of Corporate Real Estate, Vol. 18 No. 1, pp. 4-16.

Haynes, B., Suckley, L. and Nunnington, N. (2019), "Workplace alignment”, Facilities, Vol. 37 Nos 13/14, pp. 1082-1103, available at: https://doi.org/10.1108/F-07-2018-0082

Hillman, A. (2019), Towards a More Diverse and Inclusive Coworking Community, Indy Hall Blog, Philadelphia, PA, no date provided, available at: www.indyhall.org/posts/357-towards-a-morediverse-inclusive-coworking-community/ (accessed 8 September 2019).

Houtbeckers, E. (2017), "Researcher subjectivity in social entrepreneurship ethnographies the entanglement of stories in a co-working cooperative for social innovation", Social Enterprise Journal, Vol. 13 No. 2, pp. 128-243.

Jakonen, M., Kivinen, N., Salovaara, P. and Hirkman, P. (2017), “Towards an economy of encounters? A critical study of affectual assemblages in coworking", Scandinavian Journal of Management, Vol. 33 No. 4, pp. 235-242.

Jansen, W.S., Otten, S., van der Zee, K.I. and Jans, L. (2014), "Inclusion: conceptualization and measurement", European Journal of Social Psychology, Vol. 44 No. 4, pp. 370-385, doi: 10.1002/ejsp.2011.

Jylhä, T., Vuolle, M., Nenonen, S. and Virtaneva, M. (2015), “Towards business potential of workplace services in Finland", Procedia Economics and Finance, Vol. 21 No. 2015, pp. 518-523.

Kojo, I. and Nenonen, S. (2014), "Evolution of co-working places: drivers and possibilities", Intelligent Buildings International, Vol. 9 No. 3, pp. 164-175.

Kojo, I. and Nenonen, S. (2016), "Typologies for co-working spaces in Finland - what and how?", Facilities, Vol. 34 Nos 5/6, pp. 302-313.

Kokkonen, A., Esaiasson, P. and Gilljam, M. (2015), "Diverse workplaces and interethnic friendship formation - a multilevel comparison across 21 OECD countries", Journal of Ethnic and Migration Studies, Vol. 41 No. 2, pp. 284-305.

Leclercq-Vandelannoitte, A. and Isaac, H. (2016), "The new office: how coworking changes the work concept", Journal of Business Strategy, Vol. 37 No. 6, pp. 3-9.

Liegl, M. (2014), "Nomadicity and the care of place - on the aesthetic and affective organization of space in freelance creative work", Computer Supported Cooperative Work (CSCW), Vol. 23 No. 2, pp. 163-183.

Malik, A. and Manroop, L. (2017), "Recent immigrant newcomers' socialization in the workplace: roles of organizational socialization tactics and newcomer strategies", Equality, Diversity and Inclusion: An International Journal, Vol. 36 No. 5, pp. 382-400.

Malik, A., Rosenberger, P., Fitzgerald, M. and Houlcroft, L. (2016), "Factors affecting smart working: evidence from Australia”, International Journal of Manpower, Vol. 37 No. 6, pp. 1042-1066.

Marchegiani, L. and Arcese, G. (2018), "Collaborative spaces and coworking as hybrid workspaces: friends or foes of learning and innovation?", in Boccardelli, P., Annosi, M.C., Brunetta, F. and M. Magnusson, M. (Eds), Learning and Innovation in Hybrid Organizations, Palgrave Macmillan, Cham, pp. 51-71. 
Martinez, P. and Gómez, C.B. (2013), "Trading telecommuting flexibility for fewer training opportunities?”, Management Research, Vol. 11 No. 3, pp. 235-259.

Merkel, J. (2015), "Coworking in the city”, Ephemera: Theory and Politics in Organizations, Vol. 15 No. 1, pp. 121-139.

Moriset, B. (2013), "Building new places of the creative economy: the rise of coworking spaces", paper presented at the 2nd Geography of Innovation International Conference, Utrecht, 23-25 June, available at: https://halshs.archives-ouvertes.fr/halshs-00914075/document (accessed 2 September 2019).

Morrison, R.L. and Macky, K.A. (2017), "The demands and resources arising from shared office spaces”, Applied Ergonomics, Vol. 60, April, pp. 103-115, available at: www.ncbi.nlm.nih.gov/ pubmed/28166868

Nagy, G. (2019), "Corporate coworking: why companies are taking it in-house”, WorkTech Academy blogpost, no publication date provided, available at: www.worktechacademy.com/corporatecoworking/ (accessed 8 September 2019).

Nagy, G. and Lindsay, G. (2018), "Why companies are creating their own coworking spaces", Harvard Business Review, 24 September, available at: https://hbr.org/2018/09/why-companiesare-creating-their-own-coworking-spaces (accessed 8 September 2019).

Nenonen, S.P. and Lindahl, G. (2017), "Nordic workplace concept development from office as a city to city as an office", Journal of Facilities Management, Vol. 15 No. 3, pp. 302-316.

Oldenburg, R. (1989), The Great Good Place: Cafés, Coffee Shops, Bookstores, Bars, Hair Salons, and Other Hangouts at the Heart of a Community, Paragon House, New York, NY.

Orel, M. (2019), "Supporting work-life balance with the use of coworking spaces", Equality, Diversity and Inclusion: An International Journal, Ahead-of-print, available at: https://doi.org/10.1108/ EDI-01-2019-0038

Orel, M. and Alonso Almeida, M. (2019), “The ambience of collaboration in coworking environments”, Journal of Corporate Real Estate, Ahead-of-print, available at: https://doi.org/10.1108/JCRE-12-2018-0050

Parrino, L. (2015), "Coworking: assessing the role of proximity in knowledge exchange", Knowledge Management Research and Practice, Vol. 13 No. 3, pp. 261-271.

Pearce, J.L. and Randel, A.E. (2004), "Expectations of organizational mobility, workplace social inclusion, and employee job performance", Journal of Organizational Behavior, Vol. 25 No. 1, pp. 81-98.

Pelled, L.H., Ledford, G.E. Jr and Mohrman, S.A. (1999), "Demographic dissimilarity and workplace inclusion", Journal of Management Studies, Vol. 36 No. 7, pp. 1013-1031.

Petrulaitiene, V., Korba, P., Nenonen, S., Jylhä, T. and Junnila, S. (2018), "From walls to experience servitization of workplaces", Facilities, Vol. 36 Nos 9/10, pp. 525-544, available at: https://doi.org/ 10.1108/F-07-2017-0072

Pohler, N. (2012), "Neue arbeitsräume für neue arbeitsformen: coworking spaces", Österreichische Zeitschrift für Soziologie, Vol. 37 No. 1, pp. 65-78.

Raffaele, C. and Connell, J. (2016), "Telecommuting and co-working communities: what are the implications for individual and organizational flexibility?", in Sushil, Connell, J. and Burgess, J. (Eds), Flexible Work Organizations, Series: Flexible Systems Management, Springer, New Delhi, pp. 21-35.

Roth, S., Leydesdorff, L., Kaivo-Oja, J. and Sales, A. (2019), "Open coopetition: when multiple players and rivals team up", Journal of Business Strategy, Vol. ahead-of-print No. ahead-of-print, available at: https://doi.org/10.1108/JBS-11-2018-0192

Sabharwal, M. (2014), "Is diversity management sufficient? Organizational inclusion to further performance", Public Personnel Management, Vol. 43 No. 2, pp. 197-217.

Sans, V. (2016), "Corporate coworking a new way of working”, Happy Working Lab blogpost, 29 April, available at: www.happyworkinglab.com/corporate-coworking-new-way; https://www.happyworkinglab.com/corporate-coworking-new-way-working/-working/ (accessed 8 September 2019). 
JWAM

11,2

Shore, L.M., Cleveland, J.N. and Sanchez, D. (2018), "Inclusive workplaces: a review and model", Human Resource Management Review, Vol. 28 No. 2, pp. 176-189.

Shore, L.M., Randel, A.E., Chung, B.G., Dean, M.A., Holcombe Ehrhart, K. and Singh, G. (2011), "Inclusion and diversity in work groups: a review and model for future research", Journal of Management, Vol. 37 No. 4, pp. 1262-1289.

Spinuzzi, C. (2012), "Working alone together: coworking as emergent collaborative activity", Journal of Business and Technical Communication, Vol. 26 No. 4, pp. 399-441.

Statista (2018a), "Number of coworking centers in select cities worldwide in 2016", Statista - The Statistics Portal, available at: www.statista.com/statistics/722809/number-of-coworking-centersin-global-select-cities/ (accessed 16 May 2018).

Statista (2018b), "Number of people working in co-working spaces worldwide from 2010-2018", Statista - The Statistics Portal, available at: www.statista.com/statistics/554315/number-ofpeople-working-in-coworking-spaces-worldwide/ (accessed 26 April 2018).

Šviráková, E., Soukalová, R., Bednár, P. and Danko, L. (2015), “Culture managers education: system dynamics model of the coworking design centre", Procedia - Social and Behavioral Sciences, Vol. 174 No. 12, pp. 1684-1694.

van de Kar, M., Appel-Meulenbroek, R., van den Berg, P. and Arentze, T. (2017), "Employee's preferences for services and facilities offered in serviced offices: results of an empirical study", EUROFM'S 16th Research Symposium EFMC 2017, pp. 193-202.

Walden, J. (2019), "Communicating role expectations in a coworking office", Journal of Communication Management, Vol. ahead-of-print No. ahead-of-print, available at: https://doi.org/10.1108/JCOM-0 9-2018-0097

Wall, T. (2016), “Žižekian ideas in critical reflection”, Journal of Work-Applied Management, Vol. 8 No. 1, pp. 5-16, available at: https://doi.org/10.1108/JWAM-04-2016-0005

Wall, T. (2017), "A manifesto for higher education, skills and work-based learning”, Higher Education, Skills and Work-Based Learning, Vol. 7 No. 3, pp. 304-314.

Wall, T., Bellamy, L., Evans, V. and Hopkins, S. (2017), "Revisiting impact in the context of workplace research: a review and possible directions", Journal of Work-Applied Management, Vol. 9 No. 2 , pp. 95-109.

Waters-Lynch, J. and Potts, J. (2017), "The social economy of coworking spaces: a focal point model of coordination”, Review of Social Economy, Vol. 75 No. 4, pp. 417-433, available at: https://doi.org/ 10.1080/00346764.2016.1269938

Weijs-Perrée, M., Van de Koevering, J., Appel-Meulenbroek, R. and Arentze, T.A. (2017), "User preferences for co-working space characteristics", in Appel-Meulenbroek, R. and Jylhä, T. (Eds), Papers from the Workplace Research Track: 24th Annual Conference of the European Real Estate Society, ERESIDelft University of Technology, Delft, pp. 143-160, available at: https://repository. tudelft.nl/islandora/object/uuid\%3Abdd84eld-383e-4b26-b679-f654342e2fb0

WeWork (2019), "Lösungen für unternehmen (Dolutions for companies)”, no publication date, available at: www.wework.com/de-DE/enterprise (accessed 8 September 2019).

Wohlers, C. and Hertel, G. (2017), "Choosing where to work at work - towards a theoretical model of benefits and risks of activity-based flexible offices", Ergonomics, Vol. 60 No. 4, pp. 467-486.

\section{Corresponding author}

Theresa Ruwe can be contacted at: th5772ru-s@student.lu.se

For instructions on how to order reprints of this article, please visit our website:

www.emeraldgrouppublishing.com/licensing/reprints.htm

Or contact us for further details: permissions@emeraldinsight.com 